Research Article

\title{
Overhead Transmission Lines Deicing under Different Incentive Displacement
}

\author{
Qing He, ${ }^{1}$ Xi-feng Lv, ${ }^{1}$ and Xiao-tong Zhao ${ }^{2}$ \\ ${ }^{1}$ School of Energy Power and Mechanical Engineering, North China Electric Power University, Beijing 102206, China \\ ${ }^{2}$ Division of Electric Power System, China Electric Power Research Institute, Beijing 100192, China \\ Correspondence should be addressed to Xi-feng Lv; lvximin@163.com
}

Received 22 January 2014; Revised 9 June 2014; Accepted 27 June 2014; Published 13 August 2014

Academic Editor: Gongnan Xie

Copyright (c) 2014 Qing He et al. This is an open access article distributed under the Creative Commons Attribution License, which permits unrestricted use, distribution, and reproduction in any medium, provided the original work is properly cited.

\begin{abstract}
Overhead transmission line icing is one of the main factors affecting safety and reliability of power grid. This paper proposed an excitation deicing method of iced wire and theoretically revealed the ice removal mechanism under displacement excitation conditions, by taking the LGJ-70/10 glaze icing wire as the 3D model and analyzing and studying its dynamic response under the effect of displacement excitation. The simulation results show that the stress of wire icing area is enlarged with the increase of excitation displacement and frequency. Through the comparison of the compression strength experimental results on a series of different iced wires in low temperature environment, the authors found out that the stress generated from the wire icing area is greater than the crushing strength of the ice within the scope of the calculation parameters, which proved the validity and the feasibility of the method, and finally the suitable excitation displacement is determined. Following studies show that, as far as possible, it is necessary to reduce the incentive displacement and also to select the appropriate constraint length in order to avoid the line jumping that may be caused by large span ice shedding.
\end{abstract}

\section{Introduction}

Transmission line will be iced up under the environment of low temperature, freezing rain, and so forth. Ice coating of overhead transmission lines is a common natural disaster in many countries of the world. Quebec in Canada is one of the most serious areas of ice cover; ice disaster in central and southwestern America is also serious; North Caucasus in Russia, Japan, Britain, Finland, and Iceland have led to major security incidents due to the cladding ice of transmission line. Serious ice coating will influence the stability and security of power grid operation. Therefore, transmission lines deicing technology is one of the major issues of intelligent power grid construction and development which needs to be resolved.

In various transmission lines deicing methods, there are three major kinds applied in practice, such as mechanical deicing, electric melting ice, and passive method [1]. Mechanical deicing uses mechanical force to make the ice break and fall off, which mainly contains "ad hoc" method and pulley scraping method. "Ad hoc" is a kind of artificial knock deicing method; it relies on external force to percussion deicing, pulley scraping method is to eradicate the ice by artificial pulling the pulley on the line, which is a feasible mechanical deicing method on transmission lines. With the application and development of deicing robot, mechanical deicing technology obtained the expansion and development. Because of the advantages of energy saving, flexibility, and adaptability, deicing robot has increasingly become a focus of mechanical deicing on transmission lines $[2,3]$.

In the early 80 s of the last century, countries such as Canada, the United States, and Japan have started the deicing robot research and development work. Tokyo Electric Power Company in Japan in 1988 and TRC in the United States in 1989 have developed the automatic inspection robot. Hydropower Research Institute, Quebec, Canada, in 2000 developed a remote control robot. Then, Japan's Kansai Electric Power Company, Energy Systems Corporation, Tokyo Hibot Corporation, and Tokyo Institute of Technology 
researchers jointly developed "Expliner" electric robot. Line Rover, developed by Quebec Hydropower Institute, appeared early as a kind of deicing robot; it is mainly used to clean up the ice of the transmission line. In 2006, the improved inspection robot of transmission line also has the function of overcoming the barrier. At the end of 1990, some of scientific research institutions and universities in China successively launched the deicing robot research; the deicing robot from single arm robot to multiarm robot is more and more variety which is developed and improved by China Electric Power Research Institute, Shandong University, and Wuhan University. In all, the flexibility of the deicing robot is increasing [4].

In addition to the deicing robot walking mechanism, the working head part is one of the key technologies of the deicing operation success or failure. However, in the variety of deicing robots, the work head works mostly following the early method of using blade scraping and knock $[5,6]$. This is not conducive to the stable and the efficient implementation in the span flexible wire environment; what is more worth mentioning is that blade scraping and knock are easy to damage the line. After viewing the above problem, this paper proposes a local incentive displacement deicing method, which can be implemented by the working head of the deicing robot. That is, to constrain a length of iced wire, using eccentric vibrator to produce an incentive displacement to form a local vibration, the alternating stress and displacement are generated, to make ice break off from the wire, so as to realize the deicing of the icing line. In this case, the alternating displacement of the wire will be controlled by the eccentricity, which can ensure the stability of deicing operation.

In this paper, we establish the 3D glaze ice model of LGJ-70/10, focus on the analysis of cylindrical glaze ice, and investigate its distribution of stress and displacement under the incentive conditions. Then, the simulation calculation and the result were compared with the strength experimental test results of different sections of iced wire under a series of low temperature conditions. The results showed that the maximum equivalent stress under the incentive displacement of $0.25 \mathrm{~mm}$ was significantly larger than the experimental results, which proved the theoretical feasibility of this method. So, through the displacement excitation of wires, the ice can effectively be removed; in addition to the fact that the wire ice coating belongs to brittle material, alternating stress and displacement can significantly improve the efficiency of deicing and reduce the transmission lines ice load to the its allowance.

Under the condition of excitation of deicing process, adjust the appropriate incentive frequency and displacement also to investigate the stress distribution of wire ice area is a key part of the technology. In this paper, on the basis of the above calculation analysis and experimental results, the incentive conditions of the transmission lines deicing were further researched and analyzed; we summarized different incentive displacement conditions under the influence of the equivalent stress distribution of ice area in the $0-2 \mathrm{kHz}$ frequency range and finally determined the suitable incentive

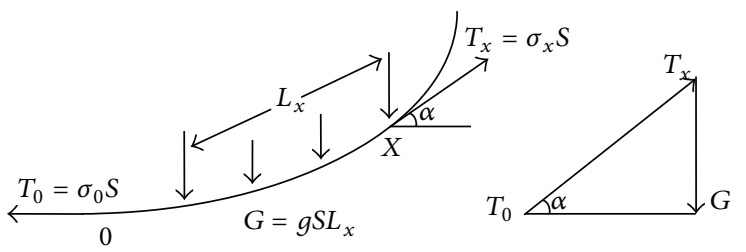

FIgURE 1: The static diagram of wire.

displacement of transmission line deicing, which has a reliable theoretical basis and reference value for the method.

\section{Wire Tension}

In the analysis of displacement excitation deicing of transmission line, wires cannot be regarded as the negligible stiffness idealized flexible cable. The dynamic response changes with the wire models, ice types, constraint length, preforce, and so forth.

Normally, within the elastic range, the preforce can correspondingly increase the stiffness of the material [7]. In the preforce (wire tension) incentive deicing technology process, a static analysis of the research object is needed. This paper discussed the uniform load isolated span iced wire tension relation and calculation method, assuming that the wire carrying is the same everywhere and is not subjected to concentrated load.

The mathematical description of wire carrying and tension is as follows.

The self-weight ratio of load is

$$
g_{1}=9.8 \times 10^{-3} \frac{m_{0}}{S} .
$$

The ice weight ratio of load is

$$
\begin{aligned}
g_{2} & =9.8 \frac{\rho V}{S L}=9.8 \times \frac{0.9 \pi(d+b) b \times 10^{-3}}{S L} \\
& =27.72 \times 10^{-3} \frac{b(d+b)}{S} .
\end{aligned}
$$

The total ratio of load is

$$
g=g_{1}+g_{2}
$$

where $m_{0}$ is the quality of wire per kilometer, $\mathrm{kg} ; S$ is the area of cross section of wire, $\mathrm{m}^{2} ; \rho$ is the density of ice, $\mathrm{kg} / \mathrm{m}^{3} ; V$ is the ice volume, $\mathrm{m}^{3} ; d$ is the diameter of wire, $\mathrm{m} ; b$ is the thickness of ice, $\mathrm{m}$; and $L$ is the length of wire, $\mathrm{m}$.

Assuming that tension and stress of the wire at the low point are, respectively, $T_{0}$ and $\sigma_{0}$ and the tension and stress of the wire at some point are, respectively, $T_{x}$ and $\sigma_{x}, \alpha$ is the angle between the tangent of the wire at some point and the horizontal direction, $S$ is the total sectional area of the wire, $g$ is the total ratio of carrier, and $L_{x}$ is the arc length from the lowest point to $X$ of any point, and then the static wire is shown in Figure 1. 


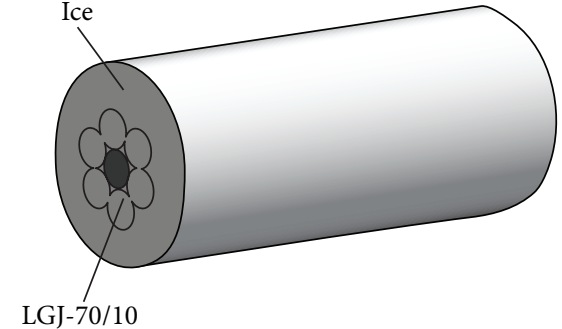

FIgURE 2: The iced wire 3D model.

TABLE 1: Mechanical parameters of the wire.

\begin{tabular}{lc}
\hline Parameter & LGJ-70/10 \\
\hline The number of aluminum/steel & $6 / 1$ \\
Diameter (aluminum/steel), mm & $3.80 / 3.80$ \\
Outer diameter, mm & 11.40 \\
\hline
\end{tabular}

The stress of the lowest point can be calculated according to the hanging curve catenary equation:

$$
y=\frac{\sigma_{0}}{g}\left(\operatorname{ch} \frac{g x}{\sigma_{0}}-1\right) .
$$

Then, according to static equilibrium conditions

$$
\begin{aligned}
& T_{x} \sin \alpha=\sigma_{x} S \sin \alpha=G=g S L_{x}, \\
& T_{x} \cos \alpha=\sigma_{x} S \cos \alpha=T_{0}=\sigma_{0} S,
\end{aligned}
$$

where $T_{x}$ is the wire tension at the $X$ point. When the tension exists, the vibration damping effect of the wire will be reduced and the bandwidth of vibration frequencies will increase, the wire is easier to start oscillation $[8,9]$. In this paper, the tension is the maximum tension of the wire at the lowest point.

\section{Wire 3D Modeling and Simulation Analysis}

3.1. Wire Parameters. The overhead transmission line adopted generally ACSR in China; wire model and the parameters are as shown in Table 1.

3.2. Ice Model. The ACSR wire modeling is extremely complex; it involves a lot of contact problems between the line and the plane, in the process of modeling; it is needed to consider the main factors affecting the analysis results and simplify the secondary factors to ensure the accuracy of theoretical calculation $[10,11]$. In the following paper, LGJ-70/10 analysis model is established and the modeling process is considered as follows.

(1) According to the actual size to build the model.

(2) In order to simplify the analysis and calculation, do small surface contact between the line and the surface.

(3) In accordance with the cylindrical ice to build the model.

The 3D glaze ice model type of LGJ-70/10 type wire is shown in Figure 2.
TABLE 2: The physical parameters of wire.

\begin{tabular}{lccc}
\hline Material & Elasticity modulus $(\mathrm{Pa})$ & Poisson's ratio & $\begin{array}{c}\text { Density } \\
\left(\mathrm{g} / \mathrm{cm}^{3}\right)\end{array}$ \\
\hline Steel & $2.06 \times 10^{11}$ & 0.3 & 7.9 \\
Aluminum & $7.17 \times 10^{10}$ & 0.33 & 2.7 \\
YuSong & $2 \times 10^{8}$ & 0.3 & 0.9 \\
\hline
\end{tabular}

3.3. Icing Type. The iced wire involves three different materials; the icing type due to the impact of meteorological parameters has the characteristics of randomness; in this paper, the authors studies the glaze ice which is common in Southern China $[12,13]$; the physical parameters are as shown in Table 2.

Among them, the elasticity modulus of glaze for this paper is the average value according to the test results of elastic modulus of 30 sets of uniaxial ice samples in the experimental environment $-15^{\circ} \mathrm{C}$ (Figure 7).

3.4. Simulation Analysis. In the simulation analysis, taking into account the feasibility of the project, the author changed the incentives displacement in the range of $0-2 \mathrm{kHz}$ incentive frequency to investigate the icing area stress distribution, under different incentive displacement; the distribution of stress contours of $y$ direction of icing area is shown in Figure 3.

The contour plot shows that the equivalent stress of the ice area in direction $y$ increases with the increase of incentive displacement; when the incentive displacement is $0.25 \mathrm{~mm}$, the equivalent stress of the ice area in direction $y$ is $9.2 \mathrm{MPa}$, and when the incentive displacement is $0.5 \mathrm{~mm}$, the equivalent stress of the ice area in the direction $y$ shows a significant increase (Figure 4).

For microscopic and direct investigation of its dynamic response, two consecutive nodes of ice area are chosen; the response curve of 4456 and 4457 nodes changed with the incentive frequency changes is shown in Figure 5.

The response curve of a continuous node shows that the stress of the ice area in direction $y$ increased linearly with the increase of incentive frequency (Figure 6). It is important to note that excessive incentive parameters will affect the stability and the safety of the transmission line deicing operations [14-17]. Therefore, it should choose the right incentives displacement and conducive incentive frequency to project implementation as the deicing technical parameters.

\section{Experiments}

In order to verify the maximum stress under the above incentive parameters which is greater than the glaze ice maximum crushing strength and select the reasonable incentive parameters, this part investigates on the strength of the ice.

The wire ice coating belongs to anisotropic brittle material and its crushing strength related to the type, temperature, geometry size, and so on [18-20]. According to the discussion of ice of International Association for Hydro Environment Engineering and Research (IAHR) in 1975 and the opinion of 


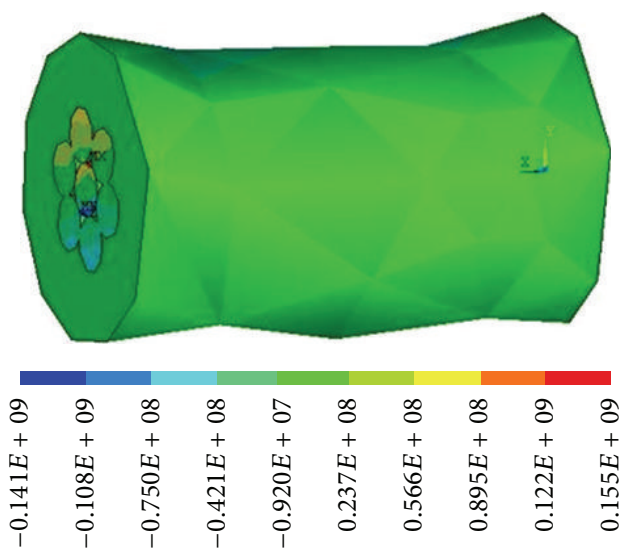

(a) $500 \mathrm{~Hz}$

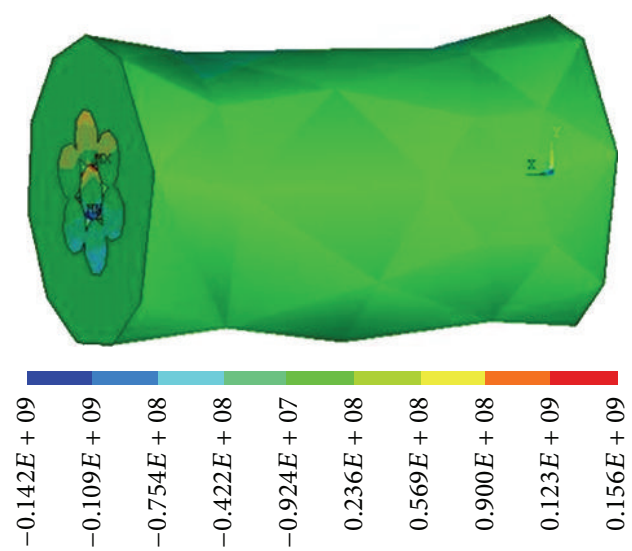

(c) $1500 \mathrm{~Hz}$

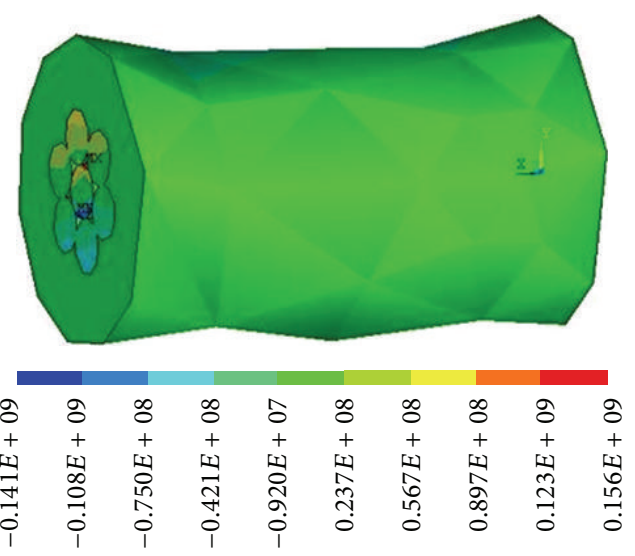

(b) $1000 \mathrm{~Hz}$

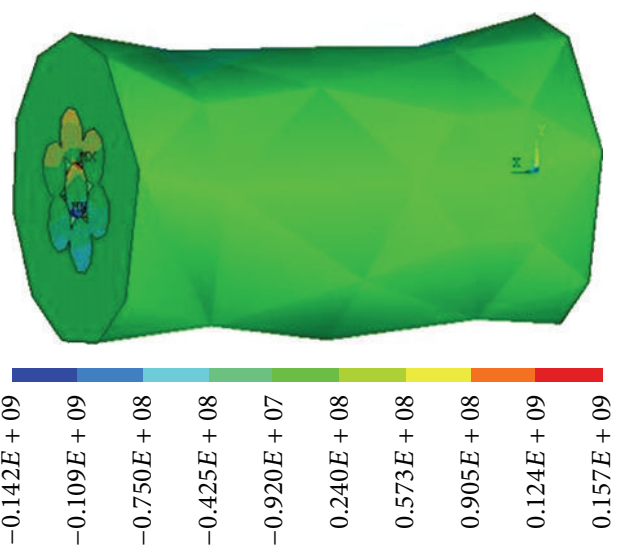

(d) $2000 \mathrm{~Hz}$

FIgURE 3: The incentive displacement of $0.25 \mathrm{~mm}$.

Committee on Ice Problems [21, 22], under low temperature environment in the laboratory, the authors ice up LGJ-70/10, LGJ-95/55, and LGJ-400/65 of three different cross section wires and processed them into $60 \mathrm{~mm}^{2}$ samples with the sectional side of $L=60 \mathrm{~mm}$ and $L=90 \mathrm{~mm}$, using the SHT4305 testing machine controlled by computer servo universal for compression test.

According to the type of the wire, the processed samples were divided into three groups and stored at $-5^{\circ} \mathrm{C},-15^{\circ} \mathrm{C}$, and $-25^{\circ} \mathrm{C}$ low temperature environment after 24 hours. It was found that, at the temperature of $-25^{\circ} \mathrm{C}$ and the compression speed of $180 \mathrm{~mm} / \mathrm{min}, \mathrm{LGJ}-95 / 55$ icing wire specimen had a maximum compressive strength of $1.3 \mathrm{MPa}$ and other cases were significantly less than $1.3 \mathrm{MPa}$; the following is the stress curve of LGJ-70/10 at $-15^{\circ} \mathrm{C}$ (Figure 8).

Collating the test results, Table 3 is the average compression strength of different icing wire samples under different temperatures.

The various experimental results show that the compressive strength of icing wire is increasing with decreasing the temperature, and at the same temperature, the compressive strength of different cross section icing wire has no
TABLE 3: The compression strength of iced sample.

\begin{tabular}{lccc}
\hline Temperature, ${ }^{\circ} \mathrm{C}$ & \multicolumn{3}{c}{$\begin{array}{c}\text { Strength, MPa } \\
\text { LGJ-95/55 }\end{array}$} \\
& LGJ-70/10 & LG-400/65 \\
\hline-5 & 0.45 & 0.78 & 1.05 \\
-15 & 0.48 & 0.93 & 1.2 \\
-25 & 0.46 & 0.84 & 1.15 \\
\hline
\end{tabular}

significant difference. At the temperature of $-5^{\circ} \mathrm{C}$, the test value is relatively stable, which is mainly concentrated in about $0.45 \mathrm{MPa}$; as the temperature decreases, the test results increased gradually, and the discrete value appears to be more obvious; at the temperature of $-25^{\circ} \mathrm{C}$, the maximum compressive strength of $1.3 \mathrm{MPa}$ appeared; the number is significantly less than the equivalent stress of 9.2 MPa under $0.25 \mathrm{~mm}$ incentive displacement; therefore, from the perspective of energy saving, high efficiency, and safety, the $0.25 \mathrm{~mm}$ incentive displacement just can realize the glaze ice broken; in addition, the higher incentive displacement will generate excessive stress and it will have a certain influence on the safety of the wire [23]. 


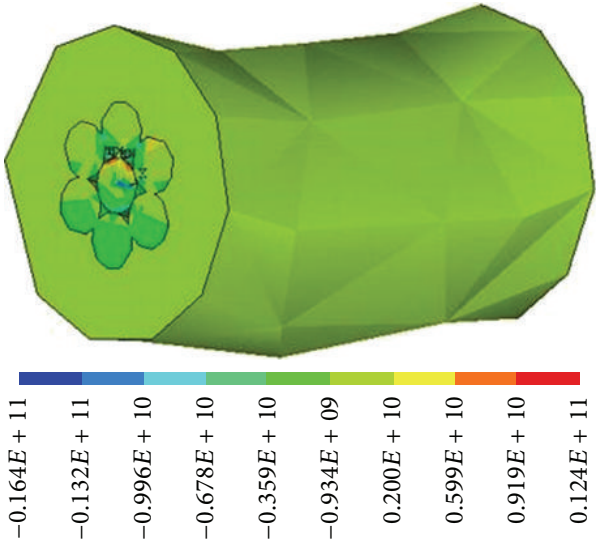

(a) $500 \mathrm{~Hz}$
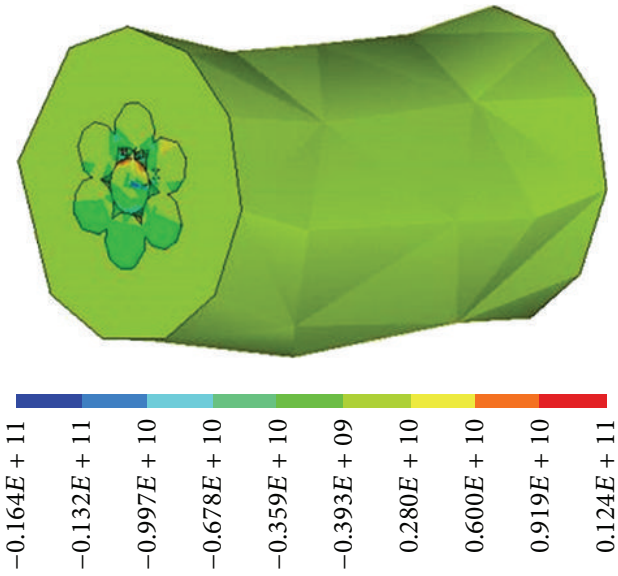

(c) $1500 \mathrm{~Hz}$

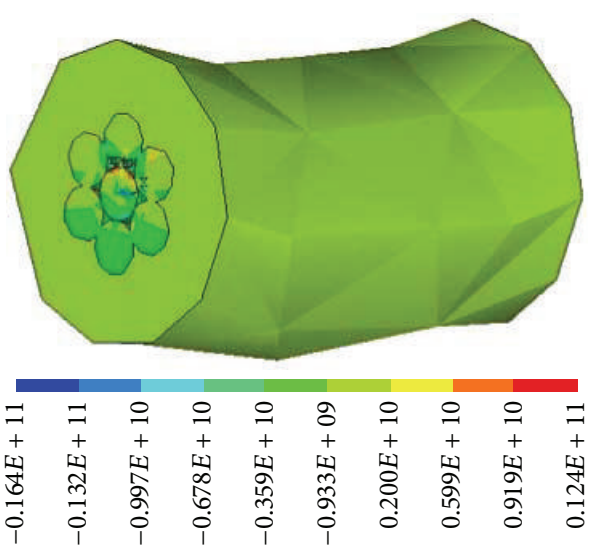

(b) $1000 \mathrm{~Hz}$
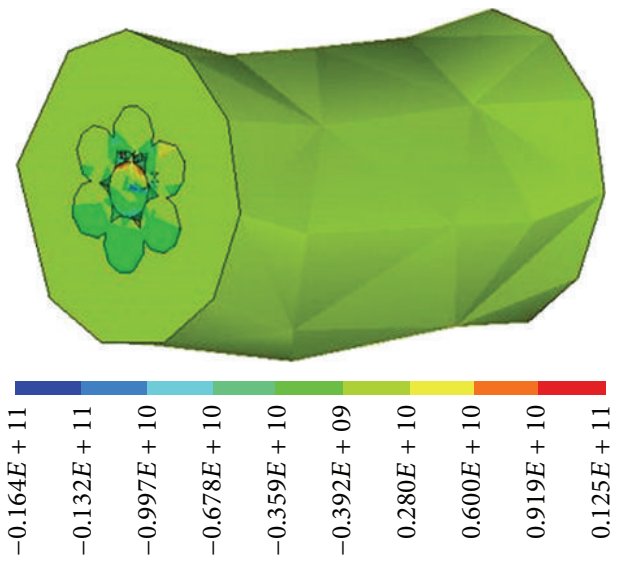

(d) $2000 \mathrm{~Hz}$

Figure 4: The incentive displacement of $0.5 \mathrm{~mm}$.

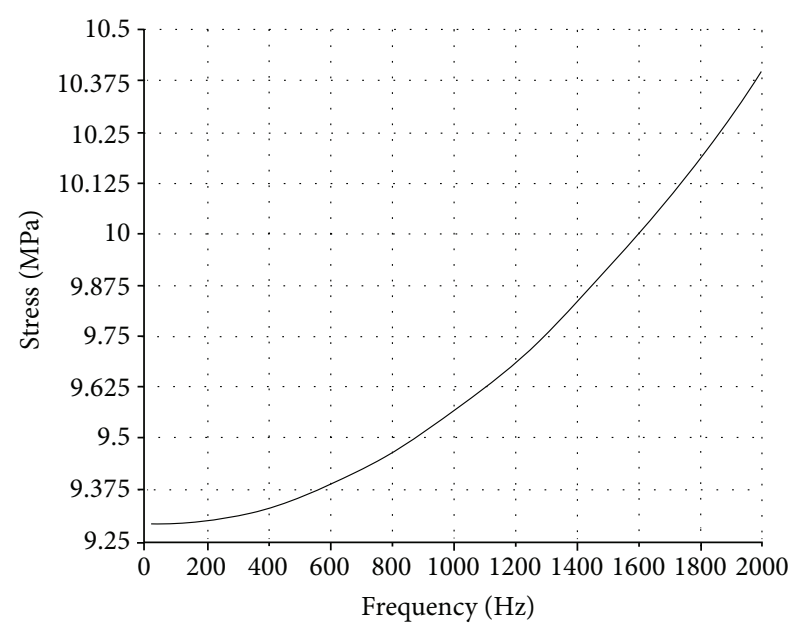

(a) The response curve of 4456 node

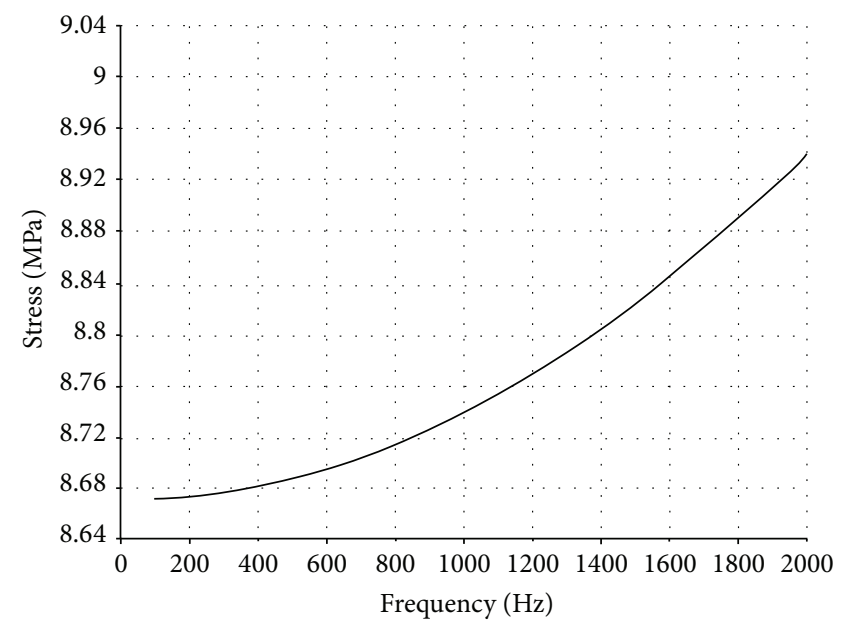

(b) The response curve of 4457 node

FIGURE 5: The displacement response curve of $0.25 \mathrm{~mm}$. 


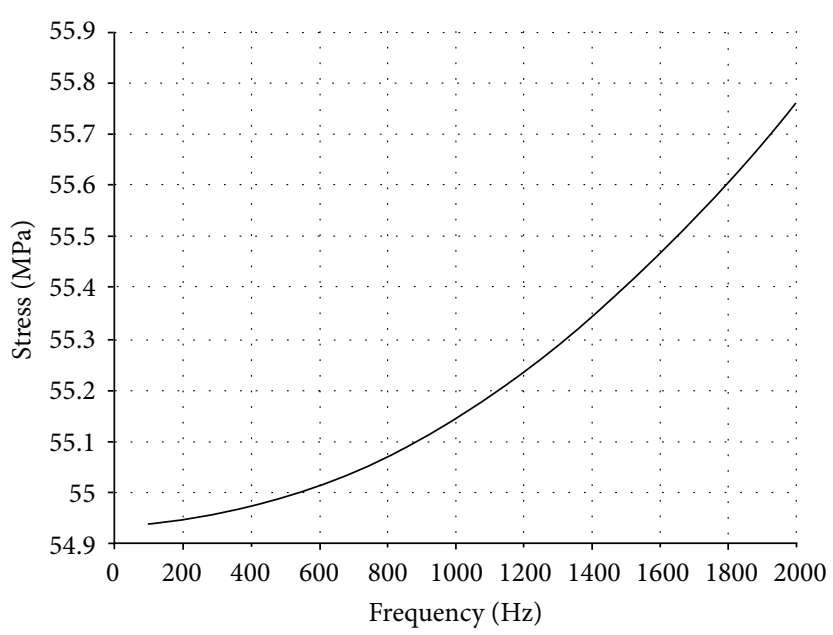

(a) The response curve of 4456 node

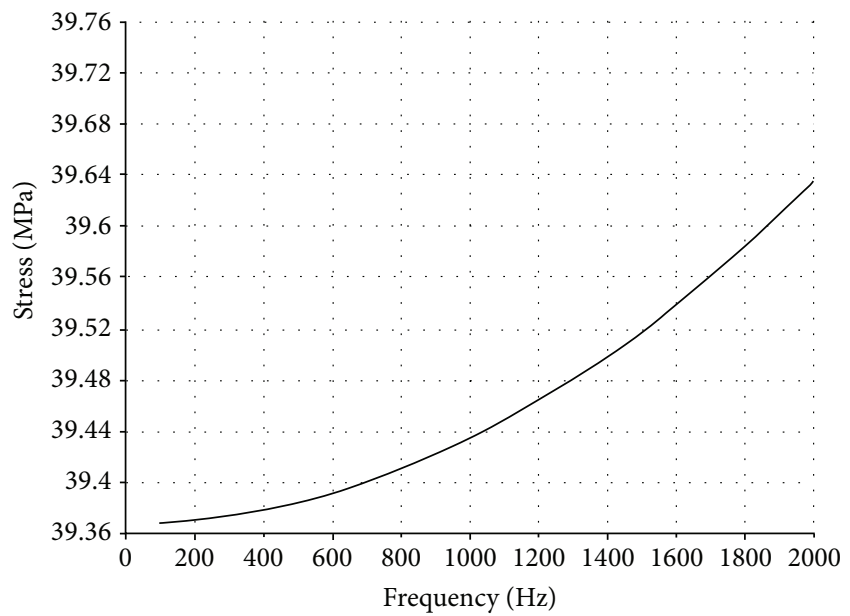

(b) The response curve of 4457 node

FIgURE 6: The displacement response curve of $0.5 \mathrm{~mm}$.

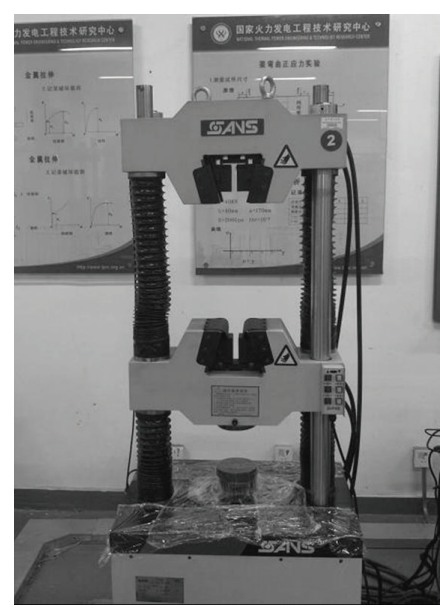

(a) SHT4305

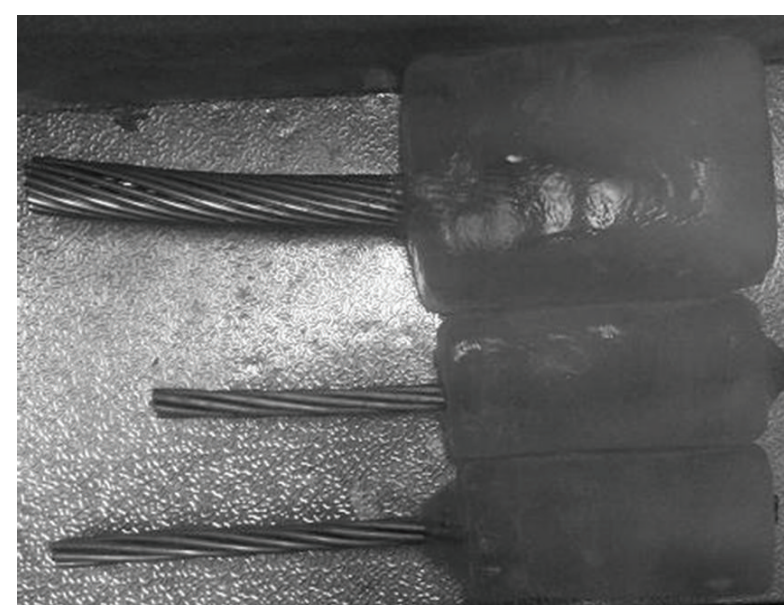

(b) Wire icing samples

FIGURE 7: Experimental equipment and samples.

\section{Structure Design and Development}

Taking into account the characteristics of flexibility and adaptability of displacement excitation deicing required, the structure is designed to be mechanical running gear which can work along the lines. It uses two groups of wheel sets to bind wire; the drive shaft is at the upper wheel. Therefore, the patrol assignments can be realized [24].

The detent spring and the pin are installed in the under of axle chute, which is easy to patrol line and which is convenient for holding force of the wire according to the thickness of the ice to adjust the wheelbase, to ensure the stability of the work. The structure in the middle is an eccentric vibrator, which is good for eccentric vibrator together with the ice wires. In addition, the eccentricity can ensure incentive displacement at the same time. The eccentric vibrator is driven by the motor to achieve the incentive on icing wire; the ice slides through the $\mathrm{V}$ groove in the middle after being broken, so as to realize the deicing of transmission line. Following is the structure diagram (Figure 9).

This structure sets the driven shaft on the above wheel through the transformation of the driving system. It also can realize independent deicing.

\section{Conclusions}

(1) The equivalent stress of icing area linearly increases as the incentive frequency increases and increases as the amount of incentive displacement increases.

(2) In the range of $0-2 \mathrm{kHz}$, under the conditions of $0.25 \mathrm{~mm}$ incentive displacement, the equivalent stress in direction $y$ of LGJ-70/10 glazing ice area is $9.2 \mathrm{MPa}$. It is significantly greater than the icing maximum compressive strength of $1.3 \mathrm{MPa}$ in laboratory. In addition, the alternating displacement will be conducive to the shedding of ice. 


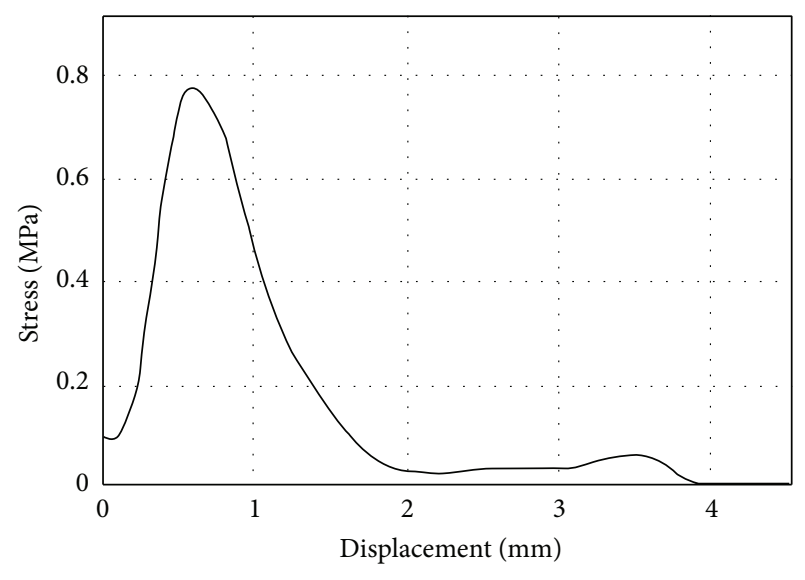

FIGURE 8: The compressive strength test curve of LGJ-70/10.

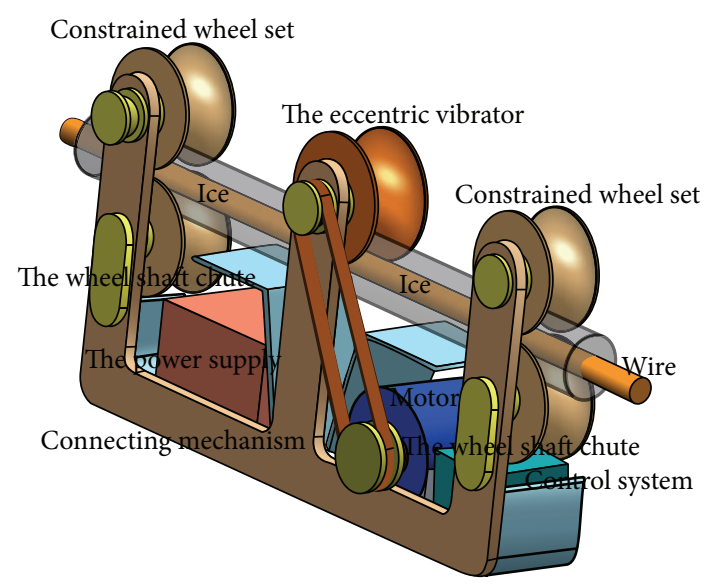

Figure 9: Structure diagram.

Therefore, the high frequency excitation deicing is feasible in theory.

(3) Considering the size and flexibility of the deicing robot, in the process of incentive deicing of transmission line, it is necessary to choose appropriate constraint length to implement, according to the simulation experience, with $0.5-1.5 \mathrm{~m}$ being appropriate.

(4) Because of the complexity of its theory and the accuracy of implementing required, the discussion of incentive deicing technology of overhead transmission line should be combined with practical experience and the engineering practice to do more comprehensive and in-depth study.

\section{Conflict of Interests}

The authors declare that there is no conflict of interests regarding the publication of this paper.

\section{References}

[1] S. Tugang, "Review of development of de-icing methods on transmission lines," Mechanical \& Electrical Engineering Magazine, vol. 25, no. 7, pp. 72-75, 2008 (Chinese).
[2] L. Chengrong, L. Yuzhen, C. Xiang et al., "Research issues for safe operation of power grid in China under ice-snow disasters," Power System Technology, vol. 32, no. 4, pp. 14-22, 2008 (Chinese).

[3] H. Xinbo, L. Jiabing, C. Wei et al., "Present research situation of icing and snowing of overhead transmission lines in China and foreign countries," Power System Technology, vol. 32, no. 4, pp. 23-28, 2008.

[4] L. Qingfeng, F. Zheng, W. Qiong et al., "Investigation of ice covered transmission lines and analysis on transmission line failures caused by ice-coating in China," Power System Technology, vol. 32, no. 9, pp. 33-36, 2008 (Chinese).

[5] X. Shan and N. Shu, "Discussion on methods of de-icing for overhead transmission lines," High Voltage Engineering, vol. 32, no. 4, pp. 25-27, 2006.

[6] S. Montambault and N. Pouliot, "The HQ LineROVer: contributing to innovation in transmission line maintenance," in Proceedings of the IEEE 10th International Conference on Transmission and Distribution Construction, Operation and Live-Line Maintenance, pp. 33-40, April 2003.

[7] L. Ping, M. Yang, L. Heng, and J. Min Qing, "Effect of bearing preload on machine tool spindle rigidity," Machine Tool \& Hydraulics, vol. 39, no. 17, pp. 9-11, 2011.

[8] T. Kálmán, M. Farzaneh, and G. McClure, "Numerical analysis of the dynamic effects of shock-load-induced ice shedding on overhead ground wires," Computers and Structures, vol. 85, no. 7-8, pp. 375-384, 2007.

[9] N. Barbieri, O. H. de Souza Júnior, and R. Barbieri, "Dynamical analysis of transmission line cables: part 2-damping estimation," Mechanical Systems and Signal Processing, vol. 18, no. 3, pp. 659-669, 2004.

[10] Q. Yuan, R. Gao, Z. Feng, and J. Wang, "Analysis of dynamic characteristics of gas turbine rotor considering contact effects and pre-tightening force," in Proceedings of the ASME Turbo Expo, Berlin, Germany, June 2008.

[11] C. Liu and J. Liu, "Ice accretion mechanism and glaze loads model on wires of power transmission lines," High Voltage Engineering, vol. 37, no. 1, pp. 241-248, 2011.

[12] L. Heyun, Z. Di, F. Jun-Ping et al., "A simple model for predicting glaze loads on wires," Proceedings of the CSEE, vol. 21, no. 4, pp. 44-47, 2001 (Chinese).

[13] X. Jiang, Z. Du, H. Wang, and Z. Zhang, "Icing features of wire in Chongqing region," High Voltage Engineering, vol. 37, no. 12, pp. 3065-3069, 2011.

[14] P. van Dyke and A. Laneville, "Galloping of a single conductor covered with a D-section on a high-voltage overhead test line," Journal of Wind Engineering and Industrial Aerodynamics, vol. 96, no. 6-7, pp. 1141-1151, 2008.

[15] L. Hou, L.-M. Wang, P.-X. Zhu, and Z.-C. Guan, "Dynamic behavior computation of ice shedding of UHV overhead transmission lines," Proceedings of CSEE, vol. 28, no. 6, pp. 1-6, 2008.

[16] Y. Lu, W. Lou, and H. Li, "Whole process analysis for nonuniform ice shedding of transmission lines," Journal of Vibration and Shock, vol. 29, no. 9, pp. 47-81, 2010.

[17] F. Yang, J. Yang, Z. Li, J. Han, and D. Fu, "Ice shedding and vibration suppression of a transmission line system," Journal of Vibration and Shock, vol. 29, no. 5, pp. 20-29, 2010 (Chinese).

[18] W. Shouli, "Study and analysis of the factors affecting wire ice coating," Power System Technology, vol. 18, no. 4, pp. 18-24, 1994 (Chinese). 
[19] C. Zhang, W. Kong, and H. Liu, "An investigation on the breakup model for icing simulation of supercooled large droplets," Acta Aerodynamica Sinica, vol. 31, no. 2, pp. 144-150, 2013.

[20] C. Zaitie, F. Qinshan, and W. Hongyu, "Non linear motion analysis on $500 \mathrm{kV}$ compact line conductor," Journal of Tsinghua University, vol. 39, no. 12, pp. 101-104, 1999 (Chinese).

[21] J. Schwarz, R. Frederking, V. Gavrillo et al., "Standardized testing methods for measuring mechanical properties of ice," Cold Regions Science and Technology, vol. 4, no. 3, pp. 245-253, 1981.

[22] N. Barbieri, O. H. de Souza Júnior, and R. Barbieri, "Dynamical analysis of transmission line cables. Part 1-Linear theory," Mechanical Systems and Signal Processing, vol. 18, no. 3, pp. 659669, 2004.

[23] G. McClure and M. Lapointe, "Modeling the structural dynamic response of overhead transmission lines," Computers and Structures, vol. 81, no. 8-11, pp. 825-834, 2003.

[24] W. Jidai, X. Yong, and W. Fengqin, "The study of mechanical structure for a power transmission line inspection robot," Machinery Design \& Manufacture, vol. 8, pp. 124-126, 2007 (Chinese). 


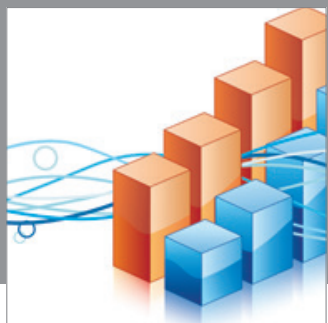

Advances in

Operations Research

mansans

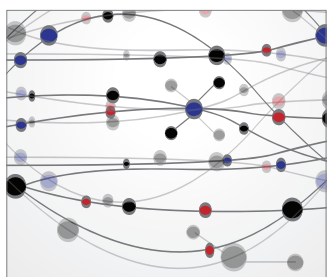

The Scientific World Journal
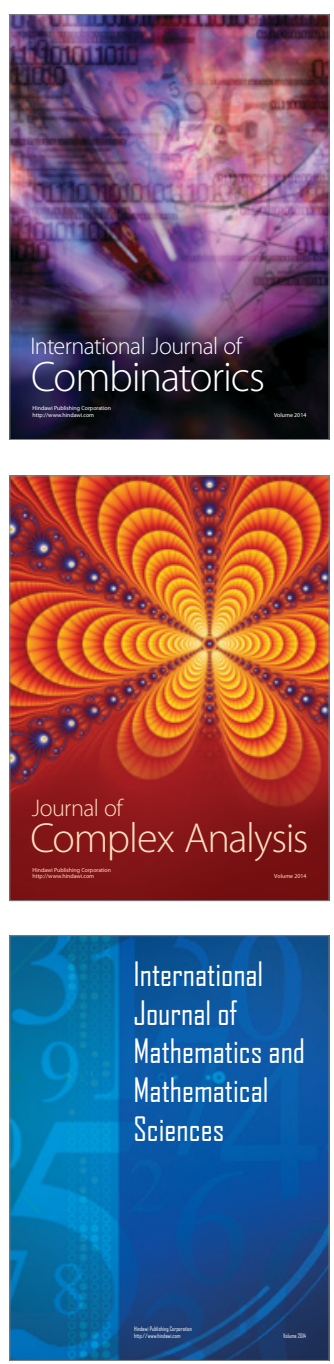
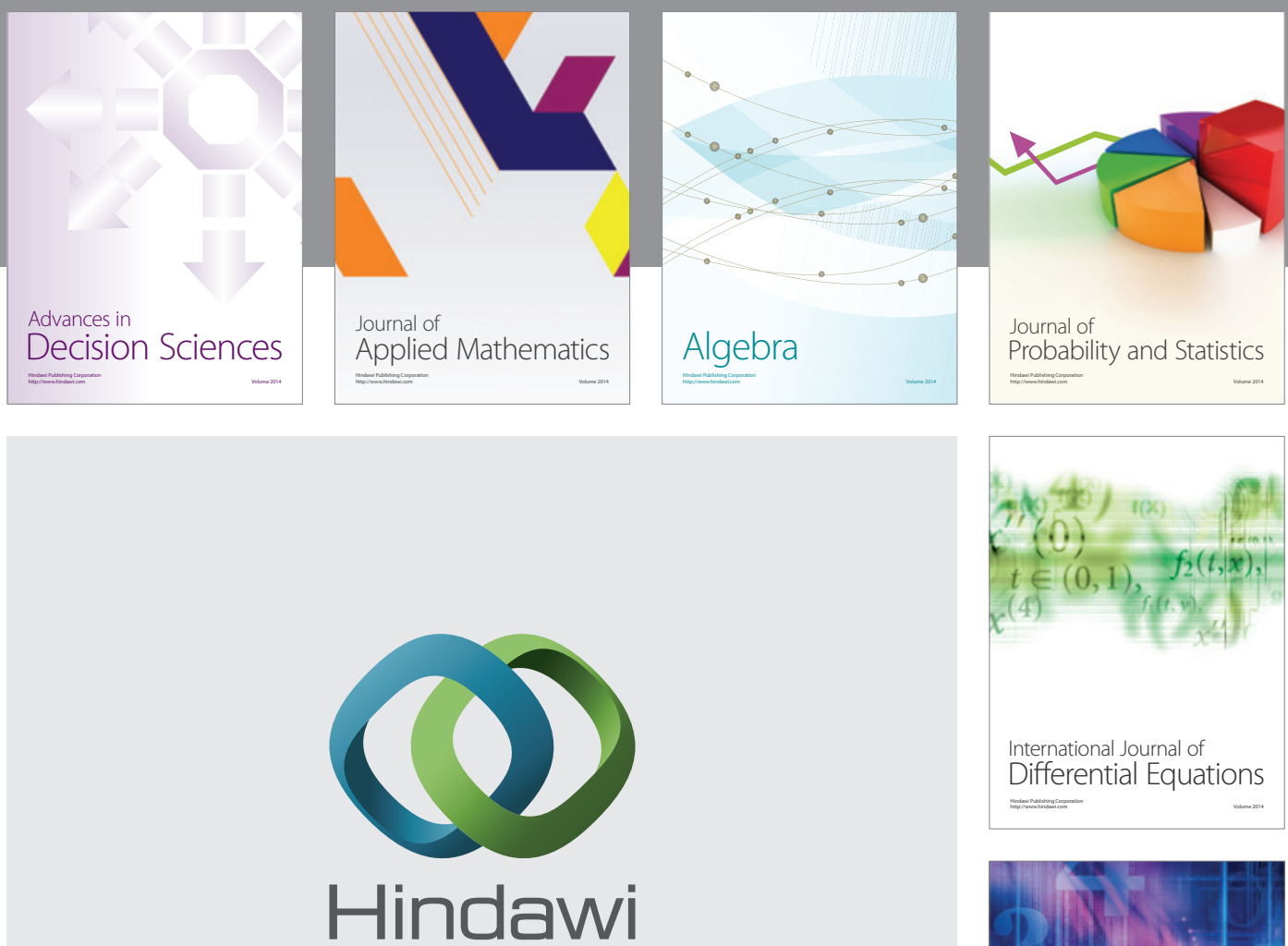

Submit your manuscripts at http://www.hindawi.com
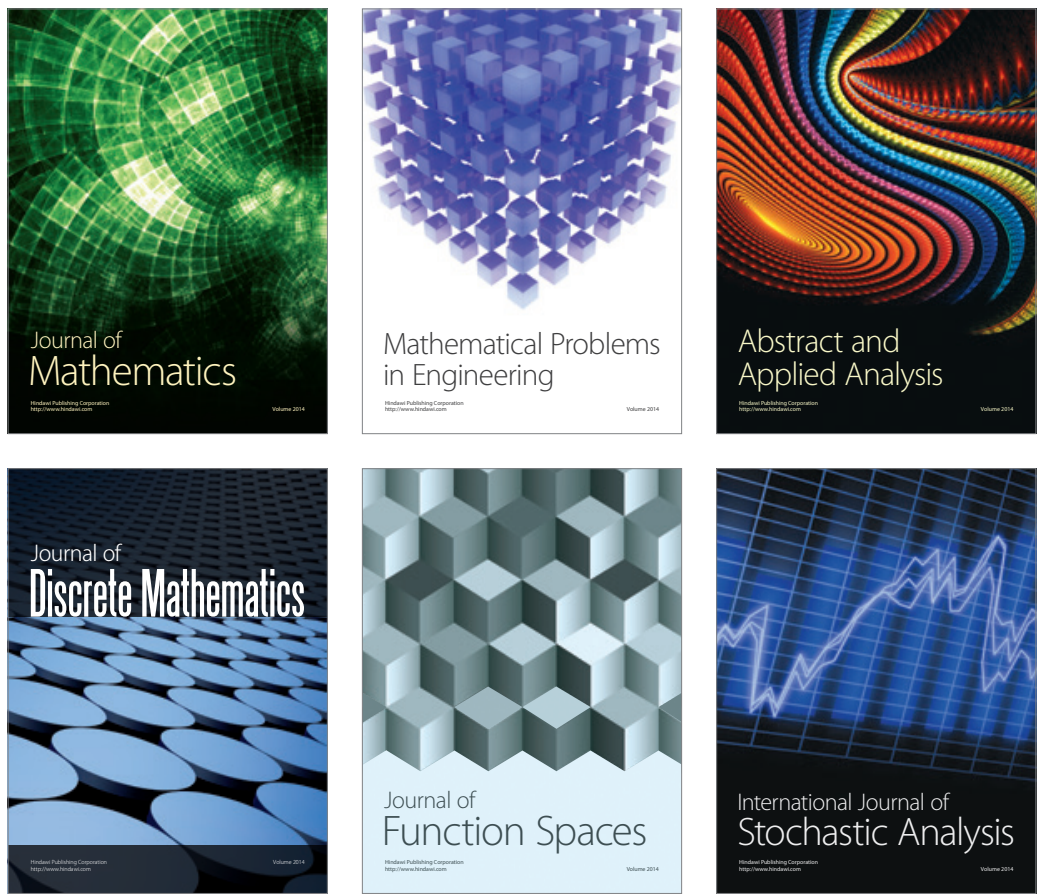

Journal of

Function Spaces

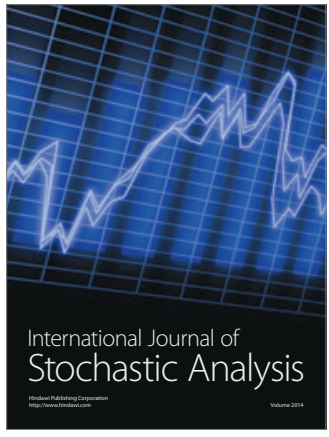

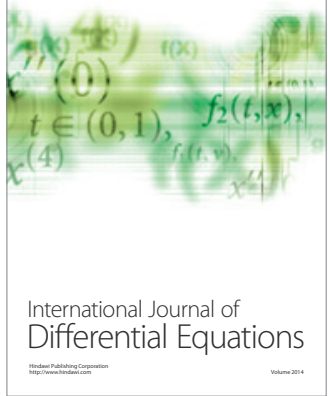
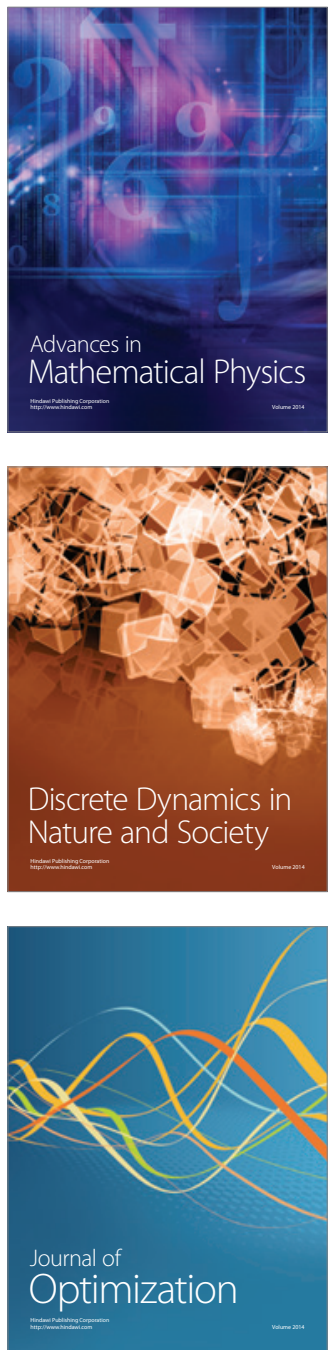